\title{
Free recall of intralist items as a function of serial position, association value and conceptualization
}

F. J. KING, IAN REID ANO DENHIS M. ROBERTS

INSTITUTE OF HUMAN LEARNING, FLORIDA STATE UNIVERSITY

Eight lists were developed each consisting of four words with high association values and four words with low association values. Words were alternated within the lists on either a high, low, high, low or a low, high, low, high scheme. Some lists had high intralist association value (a common associate for the words in the list) while others did not. The different alternation patterns modified the normal serial position curves. The presence of a common associate did not facilitate recall.

Many studies have shown that meaningful material is learned faster and retained better than less meaningful material (Underwood, 1964). The typical approach to investigation in this area has been to give two or more equated groups of Ss tasks varying in meaningfulness, with some aspect of association value being used as the meaningfulness measure. Validation data on the use of association value as a general index of meaningfulness between tasks have accumulated from various sources (Noble, 1952). Most studies, however, have been primarily concerned with inter-task learning differences rather than intra-task differences.

Recently, Roberts (1965) has shown in a study of semantic satiation, that the serial position curve of eight-item lists was in part a function of the association values of items within each list. ${ }^{1}$ The present investigation was designed to vary systematically association value within eight-item lists to further explicate the relationship between association value and recall. Method

Materials. Eight eight-item lists were derived from the concept formation materials developed by Underwood \& Richardson (1956). One list derived from the materials was: rice, flea, atom, closet, pin, minnow, pollen and crumb-with an associated descriptive adjective "small." Seven other eight-item lists were constructed using different descriptive adjective categories. The nouns within a list, however, were more or less associated with the descriptive adjective, and the association values, as published by the above authors, were indicators of this degree of association.

Low association items were defined as nouns with association values less than $53 \%$, whereas the values for the high association items were greater than $58 \%$. In Group 1, words within each of the eight lists were arranged on a $\mathrm{L}-\mathrm{H}-\mathrm{L}-\mathrm{H}$ association value basis. In Group 2, the words from each succeeding two serial positions for all eight lists were reversed, so that the items within each list were alternated on a $\mathrm{H}-\mathrm{L}-\mathrm{H}-\mathrm{L}$ association value basis. In Group 3, four of the eight lists were alternated on each of the association value schemes. Also, the words in Group 3, were grouped so that words within each list were not commonly associated with any particular descriptive adjective. Words were individually printed on transparencies and shown by a slide projector.

Procedure. Each group was told that they were to participate in a simple experiment on memory. After this, each $S$ was handed a mimeographed sheet of paper and told it would be used later in recalling certain words. The $E$ then proceeded to read the typical directions which are given in free recall studies. Ss were told that their recall of the lists did not have to be in the same order that was presented.

A 1 min. recall interval was given following each list presentation. The inter-word interval was controlled manually; however, every effort was made to keep this interval as close to 2 sec. as possible. The order of list presentation was held constant for all Ss.

Subjects. In Group 1, thirty introductory psychology students were used. In Groups 2 and 3,53 and $48 \mathrm{Ss}$ respectively were taken from undergraduate educational psychology classes. All Ss were enrolled at Florida State University.

\section{Results}

Figure 1-A presents the serial position curves for the eight-item lists for Groups 1 and 2. Also plotted

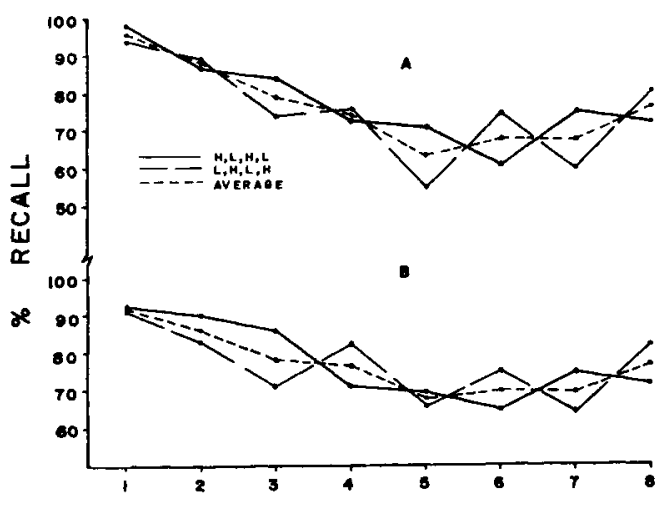

Fig. 1. Serial position curves for lists where association value was varied from position to position. 
is the average curve which theoretically represents what the serial position curve would have been if high and low association value items were distributed evenly over each position. In Group 1 it would be expected that positions $1,3,5,7$ would be relatively lower than the comparable positions in Group 2. Just the reverse relationship would be predicted for positions $2,4,6,8$. This relationship was found at every position. The probability of obtaining eight out of eight correct predictions is less than .001 (binomial expansion; $p=.5, n=8$ ). In Fig. 1-B, the serial position curves for Group 3 are presented. Again, the same up-down trend is apparent except for position 2 where no reversal was obtained. In this case the probability of being correct on seven of eight predictions is less than .01 $(\mathrm{p}=.5, \mathrm{n}=8)$.

A comparison between the average recall and serial position curves in Groups 1 and 2 (common associate available) with Group 3 (no common associate available) is presented in Fig. 2. It can be seen that the curves are highly similar. Mean recall was 6.16 and 6.13 for Group 3 and Groups 1 and 2 respectively. The difference of .03 was not significant $(t<1 ; 129 \mathrm{df})$. Discussion

Although the present study has provided evidence that the amount of recall at any given serial position is a function of association value, two points related to these findings are worth mentioning. First, the way in which Underwood \& Richardson (1956) derived associa-

\section{SERIAL POSITION}

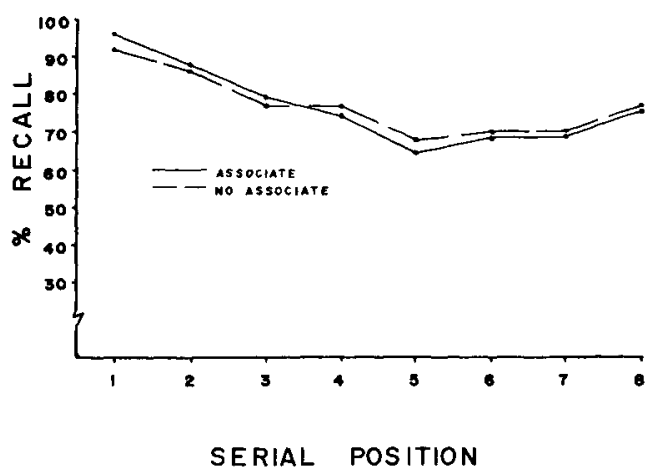

Fig. 2. Serial position curves for lists where a common descriptive associate was or was not available. tion values for their concept formation materials - that is, nouns being related to descriptive adjective categories-would lead one to restrict the usefulness of the numerical association values to the appropriate category from which it was derived. However, there seems to be a more general validity involved in these association values. This becomes apparent when looking at Fig. 1-B. These lists were rearranged so that the common associate was not available after the complete presentation of each list. Although the lists were scrambled, when dividing the eight lists into the sublists ( $\mathrm{L}-\mathrm{H}-\mathrm{L}-\mathrm{H}$ and $\mathrm{H}-\mathrm{L}-\mathrm{H}-\mathrm{L}$ ), the up-down effect is still readily noticeable. Another point related to the above discussion is that the high and low association value words, as defined in the present investigation, are not related to the Thorndike-Lorge list. By comparing the frequency of occurrence of AA, A, etc. words included in the high and low association value word groups, no relationship was found that might account for recall at any given serial position.

The fact that recall was equal when the associate was or was not available seems difficult to interpret. It would be predicted that Ss would be able to recall more words if some conceptual term were available to facilitate retention. There may be a difference between the concept attainment process and the retention of items within the concept, however. Another point which may be important is the Ss were only given one trial for each list. It seems logical, though, to expect trials to a criterion of perfect recall to be significantly different, favoring, of course, the group in which the common associate is available.

\section{References}

Noble, C. E. An analysis of meaning. Psychol. Rev., 1952, 59, 421-430.

Roberts, Dennis. The effect of proactive and retroactive satiation upon recall. Unpublished Master's Thesis, Florida State University, 1965.

Underwood, B. J., \& Richardson, J. Some verbal materials for the study of concept formation. Psychol. Bull., 1956, 53, 84-95.

Underwood, Benton $\boldsymbol{J}$. Laboratory studies of verbal learning. In Ernest R. Hilgard (Ed.), Theories of learning and instruction. Chicago: University of Chicago Press, 1964. Pp. 133-152.

\section{Note}

1. A copy of this study may be obtained by writing the Institute of Human Learning at Florida State University. 